\title{
Editorial
}

\section{Mitigating the consumption of sugar-sweetened beverages: the developing country perspective}

The current, timely, issue of this journal comes at a time health professionals are reflecting on the costs of an apparent failure to halt the obesity epidemic and its consequences in developing countries ${ }^{(1,2)}$ and the benefits of interventions directed at combating obesity and its complications ${ }^{(3,4)}$. This issue of Public Health Nutrition includes research done on sugar-sweetened beverage (SSB) consumption in a wide spectrum of countries including South Africa, China, Greece, France, Belgium, Bulgaria, Germany, Poland and Spain. This research suggests that the majority of children in these countries do not meet the recommended intake of healthy beverages (plain water and milk) ${ }^{(5-7)}$ due to the fact that they are overconsuming sugar-sweetened and carbonated beverages ${ }^{(1,5-8)}$

Prior work ${ }^{(9-13)}$ corroborates these results and further highlights the likelihood that the increased level of SSB consumption since 1999 could be fuelling the obesity epidemic in most developing countries. Energy-dense beverages (sugar-sweetened and carbonated beverages, in particular) are mostly imported into developing countries via emerging markets and food franchises. These markets and food franchises have developed strategies to increase the availability, affordability and acceptability of these beverages in developing countries ${ }^{(14)}$. As such, most of these beverages become popular due to their convenience and lower cost per unit of energy when compared with original nutrientdense beverages like dairy, fruit and vegetable juices.

The rising prevalence of obesity is unique in developing countries, since it often coexists with a high burden of undernutrition and infectious diseases. Hence, governments need to be creative in affording a high priority to and introducing targeted interventions that do not strain the already fragile economies and health systems in these countries.

The reasoning behind taxation is that if products to which sugar has been added, such as soft drinks, are taxed much in the same way as taxes are levied on products such as tobacco and alcohol, this would lead to a reduction in people's sugar intake. To date, only a few developing countries such as South Africa and Mexico as well as some European countries have responded to these calls, but only recently ${ }^{(3,15)}$. Their efforts have been motivated by the escalating obesity epidemic and its associated health complications (including diabetes and cardiometabolic diseases), especially in children and adolescents, and increasingly among those in the low socio-economic strata.
A counter-argument is that the imposition of such taxation will have a negative effect on low-income earners in the developing world and, in some cases, the negative effect will be damaging to the nation's economy if beverage producers are forced to downscale their workforce. Unfounded as this concept may be, taxation has been successful in addressing, to a variable but significant extent, tobacco and alcohol. Taxing SSB producers will encourage the industry to produce healthier options if they are to sustain their business. Moreover, taxation may encourage low-income earners in developing countries to adopt healthier practices and consume plain water or other non-sweetened beverages, and/or increase the consumption of healthier fruit and vegetables which will improve their nutrient intake ${ }^{(16)}$.

It has been shown that in fact tax interventions are associated with a reduced consumption of SSB, in addition to the motivation it creates in industry to produce healthier beverage options ${ }^{(4,9,17)}$. It also acts as a means of generating revenue that governments can use for preventing, treating and managing overall health in their countries. However, country-specific studies are needed to determine the appropriate amount of tax to discourage purchase of SSB while generating revenue that will confer a public health benefit.

Another intervention involves oversight and regulation of media advertisements for fast foods and SSB. In South Africa, Steyn et al. ${ }^{(18)}$ have recommended that food and beverage advertisements should be screened prior to being aired by the South African Broadcasting Corporation and other media outlets so as to ensure that they meet the recommendations of the Advertising Standards Authority (ASA) of South Africa ${ }^{(19)}$, and that screening committee members be nominated by the Nutrition Directorate of the Department of Health. The World Obesity Federation ${ }^{(20)}$ and Ebbeling et al. ${ }^{(17)}$ have recommended these "common sense' approaches to prevent and treat the 'public health crisis' of childhood obesity.

Despite the dearth of data on food-related advertising in developing countries, Kelly et $a l^{(21)}$ and Mchiza et $a l^{(22)}$ have shown that children in developing countries are exposed to high volumes of television advertising for unhealthy foods and beverages. According to the study by Mchiza et al. ${ }^{(22)}$, despite the existence of the ASA Code in South Africa, $10 \%$ of television advertisements in 2011 were for SSB and the advertisements appeared during family viewing time, when children were most likely to be watching 
television. Advertisers featured persuasive techniques to entice viewers, including depictions of exaggerated pleasure sensations and dependency or addiction. These depictions included statements such as 'lovely taste', 'fun and addiction sensation' and 'taste it, crave it'. Advertisers also used popular cartoon characters and attractive adolescents as well as media and prominent sporting celebrities to endorse these beverages. This type of advertising has a negative impact on children's food preferences and eating habits ${ }^{(23)}$. Hence it is important that advertisements should be screened and regulated. Regulation of advertisements in the tobacco and alcohol arena has yielded positive outcomes with regard to lowering consumption.

Amidst the rise of global obesity concern, there has also been a surge of individual products advertised as assuring quick weight loss. One such product group is nonnutritive sweeteners ${ }^{(24)}$. Manufacturers of non-nutritive sweeteners are using this as an opportunity to promote their products in developing countries and are marketing them as safe for all ages ${ }^{(24)}$. While moderate use of nonnutritive sweeteners may be useful as a dietary aid for individuals with diabetes or on a weight-loss regimen ${ }^{(25)}$, experimental studies continue to raise concerns on their use and preliminary studies would appear to associate their use with the development of obesity ${ }^{(26)}$.

So far, the only justified and legitimate intervention to counter the obesity problem is replacing the habitual consumption of SSB with plain water and milk ${ }^{(27)}$. Intervention studies ${ }^{(28-30)}$ indicate that this has a positive effect on lean body mass, body fat mass, postprandial glucose and insulin resistance, and HDL cholesterol. Helm and Macdonald ${ }^{(31)}$ have also shown that consumption of recommended levels of milk is associated with reduced risk of CVD, particularly in relation to blood pressure. A potential concern is the scarcity of clean and treated water in developing countries, and this calls for further investigation. While replacing the habitual consumption of SSB with plain water and milk is an effective intervention, additional interventions that include taxation of SSB and regulation of media advertisements should be explored.

Zandile J Mchiza, Whadi-ah Parker and Demetre Labadarios

Population Health, Health Systems and Innovation (PHHSI), Human Sciences Research Council Private Bag X9182, Cape Town 8000 South Africa Email: zmchiza@hsrc.ac.za

\section{References}

1. Tugendhaft A, Manyema M, Veerman LJ et al. (2016) Cost of inaction on sugar-sweetened beverage consumption: implications for obesity in South Africa. Public Health Nutr 19, 2296-2304.
2. Maredza M \& Chola L (2016) Economic burden of stroke in a rural South African setting. eNeurologicalSci 3, 26-32.

3. Manyema M, Veerman LJ, Tugendhaft A et al. (2016) Modelling the potential impact of a sugar sweetened beverage tax on stroke mortality, costs and health-adjusted life years in South Africa. BMC Public Health 16, 405.

4. Brownell KD, Farley T, Willett WC et al. (2009) The public health and economic benefits of taxing sugar-sweetened beverages. $N$ Engl J Med 361, 1599-1605.

5. Vieux F, Maillot M, Constant F et al. (2016) Water and beverage consumption among children aged 4-13 years in France: analyses of INCA 2 (Étude Individuelle Nationale des Consommations Alimentaires 2006-2007) data. Public Health Nutr 19, 2305-2314.

6. Pinket A, De Craemer M, Maes L et al. (2016) Water intake and beverage consumption of pre-schoolers from six European countries and associations with socioeconomic status: the ToyBox-study. Public Health Nutr 19 , $2315-2325$.

7. Farajian P, Risvas G, Panagiotakos DB et al. (2016) Food sources of free sugars in children's diet and identification of lifestyle patterns associated with free sugars intake: the GRECO (Greek Childhood Obesity) study. Public Health Nutr 19, 2326-2335.

8. Yu P, Chen Y, Zhao A et al. (2016) Consumption of sugar-sweetened beverages and its association with overweight among young children from China. Public Health Nutr 19, 2336-2346.

9. Barquera S, Hernandez-Barrera L, Tolentino ML et al. (2008) Energy intake from beverages is increasing among Mexican adolescents and adults. $J$ Nutr 138, 2454-2461.

10. Igumbor EU, Sanders D, Puoane TR et al. (2012) 'Big Food', the consumer food environment, health, and the policy response in South Africa. PLoS Med 9, e1001253.

11. Theron M, Amissah A, Kleynhans IC et al. (2007) Inadequate dietary intake is not the cause of stunting amongst young children living in an informal settlement in Gauteng and rural Limpopo Province in South Africa: the NutriGro study. Public Health Nutr 10, 379-389.

12. Colchero MA, Salgado JC, Unar-Munguía M et al. (2015) Price elasticity of the demand for sugar sweetened beverages and soft drinks in Mexico. Econ Hum Biol 19, 129-137.

13. Amarra MS, Khor GL \& Chan P (2016) Intake of added sugar in Malaysia: a review. Asia Pac J Clin Nutr 25, 227-240.

14. Powell LM \& Chaloupka FJ (2009) Food prices and obesity: evidence and policy implications for taxes and subsidies. Milbank Q 87, 229-257.

15. Bogart LM, Cowgill BO, Sharma AJ et al. (2013) Parental and home environmental facilitators of sugar-sweetened beverage consumption among overweight and obese Latino youth. Acad Pediatr 13, 348-355.

16. Zheng M, Allman-Farinelli M, Heitmann BL et al. (2015) Substitution of sugar-sweetened beverages with other beverage alternatives: a review of long-term health outcomes. J Acad Nutr Diet 115, 767-779.

17. Ebbeling CB, Pawlak DB \& Ludwig DS (2002) Childhood obesity: public-health crisis, common sense cure. Lancet 360, 473-482.

18. Steyn NP, Mchiza Z, Abrahams Z et al. (2012) Television advertising to children: ethical considerations with regard to advertising of unhealthy foods and drinks. HSRC Policy Brief. http://www.hsrc.ac.za/uploads/pageContent/6858/2014\% 20Television\%20Advertising.pdf (accessed June 2016).

19. Advertising Standards Authority of South Africa (2011) Appendix J - food and beverage code. http://www.asasa. org.za/codes/advertising-code-of-practice/appendix-j-foodand-beverage-code (accessed June 2016). 
20. World Obesity Federation (2014) Obesity prevention in children in pre-school years: policies and evidence. Report of a high-level workshop held in Brussels, 11 April 2014. http://www.worldobesity.org/site_media/uploads/Obesity_ Prevention_in_Preschool_Children.pdf (accessed June 2016).

21. Kelly B, Halford JCG, Boyland EJ et al. (2010) Television food advertising to children: a global perspective. $A m J$ Public Health 100, 1730-1736.

22. Mchiza Z, Temple NJ, Steyn NP et al. (2013) Content analysis of television food advertisements aimed at adults and children in South Africa. Public Health Nutr 16, 2213-2220.

23. Da Fonseca (2010) South African parents' perception of television food advertising directed at children. Masters in Business Administration Mini-Dissertation, North West University, Potchefstroom Campus.

24. Shankar P, Ahuja S \& Sriram K (2013) Non-nutritive sweeteners: review and update. Nutrition 29, 1293-1299.

25. de Ruyter JC, Olthof MR, Seidell JC et al. (2012) A trial of sugar-free or sugar-sweetened beverages and body weight in children. N Engl J Med 367, 1397-1406.
26. Tandel KR (2011) Sugar substitutes: health controversy over perceived benefits. J Pharmacol Pharmacother 2, 236-243.

27. Laverty AA, Magee L, Monteiro CA et al. (2015) Sugarsweetened and artificially sweetened beverage consumption and adiposity changes: national longitudinal study. Int $J$ Behav Nutr Phys Act 12, 137.

28. Albala C, Ebbeling CB, Cifuentes M et al. (2008) Effects of replacing the habitual consumption of sugar-sweetened beverages with milk in Chilean children. Am J Clin Nutr 88, 605-611.

29. Andersen LB, Arnberg K, Trolle E et al. (2016) The effects of water and dairy drinks on dietary patterns in overweight adolescents. Int J Food Sci Nutr 67, 314-324.

30. Zheng M, Rangan A, Allman-Farinelli M et al. (2015) Replacing sugary drinks with milk is inversely associated with weight gain among young obesity-predisposed children. Br J Nutr 114, 1448-1455.

31. Helm L \& Macdonald IA (2015) Impact of beverage intake on metabolic and cardiovascular health. Nutr Rev 73, Suppl. $2,120-129$. 